\title{
Pediatric self-medication use in Rwanda - a cross sectional study
}

\author{
Joyeuse Ukwishaka ${ }^{1}$, Christian Umuhoza ${ }^{1,2}$, Peter Cartledge ${ }^{1,2,3}$, Natalie McCall ${ }^{1,2,3}$
}

1. University of Rwanda

2. University Teaching Hospital of Kigali

3. Yale University (USA), Rwanda Human Resources for Health (HRH) Program, Rwanda

\begin{abstract}
Background: Self-medication, a worldwide practice, has both benefits and risks. Many countries have regulated non-prescription medications available for use in self-medication. However, in countries such as Rwanda, where prescriptions are not required to purchase medications, prescription, non-prescription and traditional medications have been used for self-medication.
\end{abstract}

Objectives: To determine the reported self-medication use in Rwanda and to determine attitudes and reasons associated with parental decisions to self-medicate their children.

Methods: A cross-sectional multi-center questionnaire based quantitative study of 154 parents/caregivers of children under ten years undertaken in private and public health facilities.

Results: The use of self-medication was reported to be $77.9 \%$. Among these parents/caregivers, $50.8 \%$ used modern self-medication only, $15.8 \%$ used traditional self-medication only and $33.3 \%$ used both types of self-medication. Paracetamol was the most commonly used drug in modern self-medication; the traditional drugs used were Rwandan local herbs. Parents/caregivers who used modern medicines had slightly more confidence in self-medication than self-medication users of traditional medicines $(\mathrm{p}=0.005)$. Parents/caregivers who used modern self-medication reported barriers to consultation as a reason to self-medicate more frequently than those who used traditional drugs. Having more than one child below 10 years of-age was the only socio-demographic factor associated with having used self-medication (AOR=4.74, CI: 1.9411.58, $\mathrm{p}=0.001)$. Being above 30 years $(\mathrm{AOR}=5.78, \mathrm{CI}: 1.25-26.68, \mathrm{p}=0.025)$ and living in Kigali $(\mathrm{AOR}=8.2$, CI: 1.58-43.12, $\mathrm{p}=.0 .012$ ) were factors associated with preference of modern self- medication compared to traditional self-medication.

Conclusion: Self-medication is common in Rwanda. Parents/caregivers are involved in this practice regardless of their socio-demographic background.

Keywords: Self-medication; medicines; parents; caregivers; children; Nonprescription Drugs; Rwanda.

DOI: https://dx.doi.org/10.4314/ahs.v20i4.61

Cite as: Ukwishaka J, Umuboza C, Cartledge P, McCall N. Pediatric self-medication use in Rwanda - a cross sectional study. Afri Health Sci. 2020;20(4):2032-43. https:// dx.doi.org/10.4314/abs.v20i4.61

\section{Introduction}

Since the declaration of Alma-Ata in 1978, the principles of self-care, individual participation, responsibility and involvement in one's own health care have been recognized as important elements of primary healthcare ${ }^{1-3}$. Self-care includes self-medication which the WHO defines as "the selection and use of medicines by individuals to treat self-recognized illnesses or symptoms" ${ }^{\prime-7}$. In the pediatric population, self-medication

\section{Corresponding author:}

Joyeuse Ukwishaka,

University of Rwanda

Phone: +250788568498

E-mail: ukwishakajoy@gmail.com implies administration of a drug to a child, by a caregiver, without prior medical consultation ${ }^{8}$. WHO defines traditional medicine as "The sum of knowledge, skill, and practices based on the theories, beliefs, and experiences indigenous to different cultures, whether explicable or not, used in the maintenance of health as well as in the prevention, diagnosis, improvement or treatment of physical and mental illness" ${ }^{9,10}$. Traditional medicines will often be chosen and provided by a traditional healer or therapist, but can also be produced or purchased by an individual and used as a form of self-medication.

Responsible self-medication implies the use of approved, safe, and effective drugs, accompanied by information to direct users ${ }^{11}$. There are several advantages of responsible self-medication, but the pop-

(C) 2020 Ukwishaka J et al. Licensee African Health Sciences. This is an Open Access article distributed under the terms of the Creative commons Attribution License (https://creativecommons.org/licenses/BY/4.0), which permits unrestricted use, distribution, and reproduction in any medium, provided the original work is properly cited. 
ulation must be aware of potentials risks and harms of self-medication ${ }^{12,13}$.

Factors associated with the parental choice to self-medicate their children vary, but include: parents/caregivers perceiving their child's illness as being mild and not requiring health professional consultation, lack of time to attend consultations, high consultation fees, clinic waiting time, emergency treatment, use of old prescriptions available in the home, parent comfort in recognizing their children's disease based on the symptoms and having experience with the medication ${ }^{14,15}$.

Pediatric self-medication is a worldwide practice with a reported prevalence between 32-98\% in Madagascar, India, Greece, and Australia ${ }^{8,16-18}$. Tanzania, a fellow nation of the East African community has reported pediatric self-medication rates of $69 \%{ }^{19}$.

There is also a difference in education and economic factors associated with the choice to self-medicate. Studies from Spain, Finland, Italy, and Madagascar 12,19-21, found that families with high income and with secondary and higher education level practice more self-medication than families with low income and low education level. On the other hand, in studies done in Germany and India, family income and parental education were not significantly influencing self-medication practice $^{9,22}$.

There is insufficient literature describing the use of self-medication in pediatric populations in Sub-Saharan Africa. In Rwanda, self-medication is being used by parents/caregivers for their children ${ }^{20,21}$. The Rwandan Ministry of Health regulates essential medicines in accordane with WHO recommendations but there is no regulation of non-prescription or OTC drugs. In addition, there is a rise in antibiotic resistance in the country. Self-medication, if not done in a responsible and safe manner, could predispose the population to more harm than benefits. So there is a need to establish a baseline data on parental self-medication practices in Rwanda including the use of traditional and modern drugs. This could help health care providers and policymakers to plan education and establish policies aiming to achieve responsible use of medicines.

Objectives The present study aimed at determining the proportion of parents/caregivers who reported self-medicating their children before consulting private and public health facilities in Rwanda and to determine attitudes and reasons associated with parental decisions to self-medicate their children.

\section{Methods}

Study Design: We conducted a cross-sectional study from July to September 2018. Reporting has been verified in accordance with the STROBE (Strengthening the Reporting of Observational Studies in Epidemiology) checklist ${ }^{22}$.

Study Sites/settings: We conducted a multi-center study in three facilities: i) a provincial referral hospital, two hours from Kigali, the capital of Rwanda, ii) a vaccination clinic in an urban public health center in Kigali city and iii) a private pediatric clinic in Kigali, which serves a larger proportion of educated parents/caregivers with high socioeconomic level. This selection was done to increase the representativeness and generalizability of the results to the Rwandan Population.

Study population: The study aimed to recruit parents / caregivers of both unwell and well children with different socioeconomic status. Unwell children were recruited at out and in-patient units of one private and one public health facility. Parents/caregivers of well children were approached at a vaccination clinic in a health center.

Inclusion criteria: All Rwandan parents/caregivers of children aged one month to 10 years of life and who accepted to participate in the study were eligible to be included. Parents/caregivers who were not primary caregivers of the children were excluded as they would not be able to describe fully the self-treatment of the children. We excluded from the analysis the participants who consented but did not fully complete the questionnaire.

Sampling: Non-probability convenience sampling was used to recruit study subjects on working days (Monday to Friday) during working hours (8am to $5 \mathrm{pm}$ ).

Procedures for enrollment: Eligible parents/caregivers were approached in the waiting area, prior to their consultation, and they were given a verbal explanation of the purpose and the methods of the study. All participants who signed the written consent form were then included. No data was kept on the number of participants who declined to participate.

Administering the questionnaire: Questionnaires were given to parents/caregivers by the PI or a trained 
data collector (DC) who was available to answer questions regarding the questionnaire. For parents/caregivers who couldn't read or who preferred to be assisted, the DC read the questions and completed the questionnaires on behalf of the participant. The questionnaires were completed in the waiting area of the respective health facility. When the questionnaire was filled by the DC, this was indicated on the form.

Variables: Dependent (outcome) variable were the percentage of parents/caregivers using self-medication, reasons of parental self-medication and common drugs used in self-medication. Independent variables were age, sex, province of origin, level of education, socioeconomic status, number of children under 10 years of age; health insurance, determinant/predictors of parental self-medication, relationship with the child, marital status. Potential confounders were site of interview and mode of completing questionnaire (verbal or written)

Data collection tool (Questionnaire): A questionnaire was developed specifically for this study. To ensure content validity of our data collection tool, it was first built by the Principal Investigator (PI) (JU) using previously published studies ${ }^{14,15,23-25}$. The first draft was then reviewed by four local experts in research (three pediatricians (CU, NM \& PC) and one statistician). There were four sections to the questionnaire, namely: demo- graphic characteristics of respondents; modern medicine questionnaire; traditional medicine questionnaire and finally the no self-medicating questionnaire. Parents/caregivers were asked whether they have ever used self-medication for their children and if so, what type they had used. Depending on their answers, they completed the appropriate questionnaire (i.e. Modern and/or Traditional medicines) or the questionnaire for parents/caregivers who have never used self-medication for their children. Therefore, not all subjects completed all sections of the questionnaires

The questionnaires used 5-point Likert-scales to assess the parental attitudes and perceptions about self-medication. The responses given to the Likert-scale questions from each of the barriers (five questions) and confidence (six questions) domains were combined to create total "barriers to consultation" and total "confidence in self-medicating" scores.
Translation and piloting of questionnaires: The questionnaire was initially prepared in English and translated into the national language (Kinyarwanda) by the PI. It was then back-translated in English for accuracy by an independent, non-medical translator. It was piloted on five subjects and amendments were then made based on this piloting, including changes in wording and the addition of further Likert-items.

Sample size calculation: Sample-size was calculated for the prevalence of self-medicating, with a predicted baseline of $69 \%$ of parents/caregivers of children under-five years of age reported in Tanzania ${ }^{19}$. Using the formula with Finite Population Correction ${ }^{26}$ and a level of confidence aimed at $95 \%$ we calculated the sample size to be 152 study participants.

Data management: EpiData Entry 3.1 Software was used for data entry and storage. The data was then exported into Statistical Package for the Social Sciences (IBM Corp. Released 2011. IBM SPSS Statistics for Windows, Version 20.0. Armonk, NY: IBM Corp.), for statistical analysis.

Statistical analysis: For continuous numerical data, means and standard deviation were reported; for categorical data, frequency tables, percentages and graphs were reported. Comparison was made between responses on the modern-medicine and traditional-medicine questionnaires. Therefore, parents/caregivers, who self-medicated with both modalities, were included in both arms of the analysis For confidence and barrier questions, Likert-scale items were converted into means and compared using Mann-Whitney $U$ test due to the non-normal distribution of the data. Categorical variables were analyzed using Chi-square test or Fisher's exact test. Odds ratio were reported to identify associations. To account for multiple confounders logistic regression analysis was undertaken including variables with p-value $<0.2$.

\section{Results}

Study period: Recruitment took place from July to September 2018 with all sites being visited twice, gaining a total of 162 subjects who were enrolled (Figure 1). 


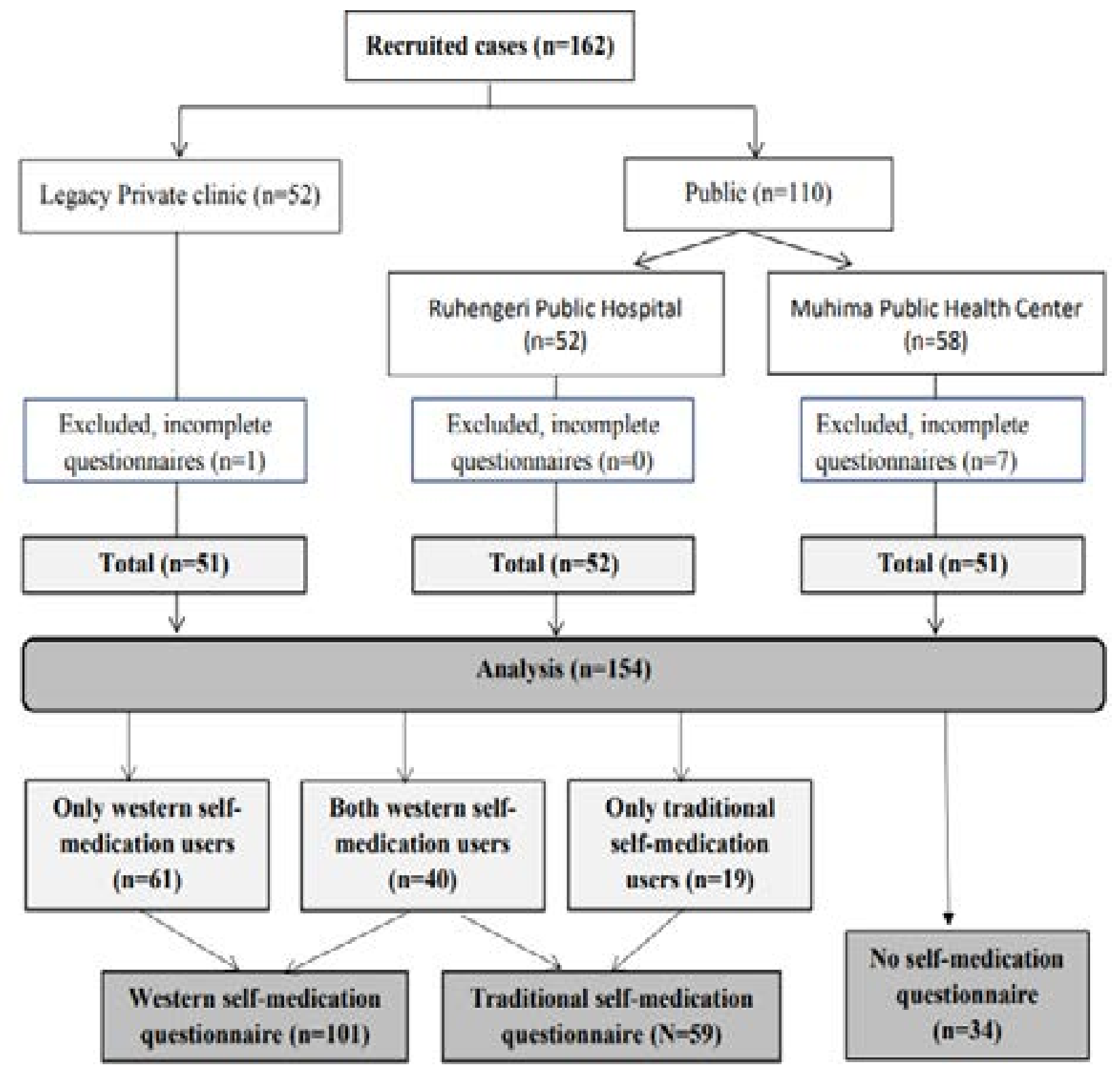

Figure 1: Consort flow diagram ( $n=$ number of respondents, $N=$ Number of participants)

Participation flow and social-demographic characteristics: Eight participants were excluded from the analysis as they did not complete the questionnaires fully, leaving a total of 154 participants who were included in the final analysis with complete data. Fourteen participants $(9 \%)$ self-completed the questionnaire with $140(91 \%)$ needing assistance with verbal completion of the questionnaire. The mean age of respondents was 33 years (SD: 6.7). Mothers represented the major- ity $(86.4 \%)$ of respondent and most respondents were married (94\%) (Table 1).

Self-medication indications and practices: Among 154 participants, 120 caregivers $(78 \%)$ reported to have used self-medication for their children, Sixty-one of them $(51 \%)$ used only modern drugs in self-medication, $19(16 \%)$ used only traditional drugs while $40(33 \%)$ used both types. Thirty-four caregivers had never used self-medication $(22 \%)$ (Figure 1). 
Table 1: Participant demographics

\begin{tabular}{llll} 
Item & Classification & Frequency & Percentage \\
\hline Site of interview & Private & 51 & $33.1 \%$ \\
& Public & 103 & $66.9 \%$ \\
\hline Origin & Kigali & 92 & $59.7 \%$ \\
& Outside Kigali & 62 & $40.3 \%$ \\
\hline Relationship & Mother & 133 & $86.4 \%$ \\
& Other & 21 & $13.6 \%$ \\
\hline Marital status of parent & Married & 145 & $94.2 \%$ \\
& Single (+ Separated, Widowed) & 9 & $5.8 \%$ \\
\hline Age of parent & $\leq 30$ & 60 & $39 \%$ \\
& $>30$ & 94 & $61 \%$ \\
\hline Education level & Advanced & 77 & $50 \%$ \\
\hline Economic status & Minimal & 77 & $50 \%$ \\
\hline Health insurance & High & 45 & $29.2 \%$ \\
& Low and Middle & 109 & $70.8 \%$ \\
\hline 10yrs & Private & 60 & $39 \%$ \\
\hline Number of children under & Mutuelle de santé & 89 & $57.8 \%$ \\
& None & 5 & $3.2 \%$ \\
\hline & 1 & 48 & $31.2 \%$ \\
\hline & $>1$ & 106 & $68.8 \%$ \\
\hline
\end{tabular}

Advanced education level = completed secondary school or university; Minimal education level = no education or completed primary school; High economic status = have both employment and own house; Middle economic class $=$ have either employment or own house; Low economic class = have neither employment nor own house;

Many parents/caregivers decided to self-medicate with modern medications without seeking advice from anyone. Whereas, for traditional self-medication, friends and relatives served as the main sources of advice ( $\mathrm{Ta}$ - ble 2). All traditional self-medication users used local Rwandan herbs. Paracetamol was the most commonly used modern medicine. Traditional medicine was most commonly used when parents/caregivers suspected intestinal worms. 
Table 2: Self-medication indications and practice

\begin{tabular}{|c|c|c|c|}
\hline Item & Classification & $\begin{array}{l}\text { Modern medicine } \\
\mathrm{s}(\mathrm{N}=101)\end{array}$ & $\begin{array}{l}\text { Traditional } \\
\text { medicine }(\mathrm{N}=59) \\
\end{array}$ \\
\hline \multirow[t]{6}{*}{ Source of advice before deciding to use self-medication } & Myself & $54(53.4 \%)$ & $14(23.7 \%)$ \\
\hline & Health care provider & $32(31.7 \%)$ & $0(0 \%)$ \\
\hline & Friend/relative & $17(16.8)$ & $36(61.0 \%)$ \\
\hline & Internet/media & $5(5.0 \%)$ & $5(8.5 \%)$ \\
\hline & Traditional healer & $1(1.0 \%)$ & $11(18.6 \%)$ \\
\hline & Other & $2(1.9 \%)$ & - \\
\hline \multirow[t]{8}{*}{ Symptom for which self-medication is given } & Fever & $78(77.2 \%)$ & $3(5.1 \%)$ \\
\hline & Cough and runny nose & $44(43.6 \%)$ & $16(27.1 \%)$ \\
\hline & Intestinal worms & $15(14.8 \%)$ & $20(33.8 \%)$ \\
\hline & Pain & $6(5.9 \%)$ & $1(1.7 \%)$ \\
\hline & Difficult breathing & $5(5.0 \%)$ & $2(3.4 \%)$ \\
\hline & Diarrhea/vomiting & $5(5.0 \%)$ & $13(22.0 \%)$ \\
\hline & Skin conditions & $3(3.0 \%)$ & $5(8.5 \%)$ \\
\hline & Others & $15(14.8 \%)$ & $17(28.8 \%)$ \\
\hline \multirow[t]{8}{*}{ Source of medications } & Pharmacy & $94(93.1 \%)$ & - \\
\hline & Leftover medicine & $15(14.9 \%)$ & - \\
\hline & $\begin{array}{l}\text { Health care facility w/0 } \\
\text { prescription }\end{array}$ & $5(5.0 \%)$ & - \\
\hline & Shop/store & $1(1.0 \%)$ & - \\
\hline & Relative/friend & $0(0 \%)$ & $5(8.5 \%)$ \\
\hline & Traditional healer & - & $22(37.3 \%)$ \\
\hline & Self-collected herbs/plants & - & $36(94.7 \%)$ \\
\hline & Others & - & $2(5.2 \%)$ \\
\hline \multirow{4}{*}{$\begin{array}{l}\text { Type of Health care facility consulted in case of self- } \\
\text { medication failure }\end{array}$} & Private & $47(46.5 \%)$ & $9(15.3 \%)$ \\
\hline & Public & $38(37.6 \%)$ & $23(39.0 \%)$ \\
\hline & Traditional healer & $5(5.0 \%)$ & $5(8.5 \%)$ \\
\hline & None & $24(23.7 \%)$ & $26(44.1 \%)$ \\
\hline \multirow{8}{*}{$\begin{array}{l}\text { Drugs used in self-medication with modern medications } \\
(\mathrm{n}=101)\end{array}$} & Paracetamol & $73(72.3 \%)$ & - \\
\hline & Cough Syrup & $40(39.6 \%)$ & - \\
\hline & Ibuprofen & $29(28.7 \%)$ & - \\
\hline & Antibiotics & $18(17.8 \%)$ & - \\
\hline & Drugs for intestinal worms & $17(16.8 \%)$ & - \\
\hline & Skin preparation & $4(4 \%)$ & - \\
\hline & Oral Rehydration Solution (ORS) & $3(3 \%)$ & - \\
\hline & Others & $15(14.8 \%)$ & - \\
\hline
\end{tabular}

Respondents could choose more than two options.

Reasons for using self-medication: There was a statistically significant difference in reasons for choosing modern and traditional self-medication among our participants, with participants choosing modern medications having slightly more confidence in self-medication than self-medication providers of traditional medicines $(p=0.005)$ and parents/caregivers who used modern self-medication reporting barriers to consultation more frequently as reason to self-medicate than parents/caregivers who used traditional self-prescription $(\mathrm{p}=0.028)$ (Table 3). 
Table 3: Reasons of using self-medication - Means of Likert questions

\begin{tabular}{|c|c|c|c|c|c|c|c|c|c|}
\hline & \multicolumn{4}{|c|}{ Modern Medicine (n=101) } & \multicolumn{4}{|c|}{ Traditional medicine $(\mathrm{n}=59)$} & \multirow[t]{2}{*}{ p-value } \\
\hline & Disagree & Neutral & Agree & Mean $( \pm$ SD) & Disagree & Neutral & Agree & Mean $( \pm$ SD) & \\
\hline \multicolumn{10}{|c|}{ Confidence in self-prescribing } \\
\hline $\begin{array}{l}\text { The symptoms of my } \\
\text { child are minor and do } \\
\text { not require a health } \\
\text { facility consultation }\end{array}$ & $29(28.8 \%)$ & $0(0 \%)$ & $72(71.2 \%)$ & $3.56( \pm 1.08)$ & $23(40 \%)$ & $1(1.7 \%)$ & $35(59.3 \%)$ & $3.31( \pm 1.14)$ & $\mathrm{p}=0.164$ \\
\hline $\begin{array}{l}\text { I can recognize my } \\
\text { child's disease based on } \\
\text { his/her symptoms }\end{array}$ & $35(34.7 \%)$ & $0(0 \%)$ & $66(65.3 \%)$ & $3.39( \pm 1.07)$ & $27(45.8 \%)$ & $0(0 \%)$ & $32(54.2 \%)$ & $3.22( \pm 1.21)$ & $p=0.477$ \\
\hline $\begin{array}{l}\text { I have used drug } \\
\text { previously }\end{array}$ & $24(23.8 \%)$ & $1(1 \%)$ & $76(75.2 \%)$ & $3.64( \pm 1.04)$ & $24(40.8 \%)$ & $0(0 \%)$ & $35(59.3 \%)$ & $3.31( \pm 1.22)$ & $\mathrm{p}=0.111$ \\
\hline $\begin{array}{l}\text { I want to give } \\
\text { emergency treatment to } \\
\text { my child }\end{array}$ & $13(12.9 \%)$ & $1(1 \%)$ & $87(86.1 \%)$ & $3.83( \pm 0.81)$ & $31(52.6 \%)$ & $0(0 \%)$ & $28(47.4 \%)$ & $3.00( \pm 1.17)$ & $\mathrm{p}<0.001$ \\
\hline $\begin{array}{l}\text { Non-prescription } \\
\text { medicines work well }\end{array}$ & $27(26.7 \%)$ & $6(6 \%)$ & $68(67.3 \%)$ & $3.37( \pm 1.02)$ & $20(34 \%)$ & $3(5 \%)$ & $36(61 \%)$ & $3.27( \pm 1.04)$ & $\mathrm{p}=0.558$ \\
\hline $\begin{array}{l}\text { Non-prescription } \\
\text { medicines are not } \\
\text { dangerous }\end{array}$ & $28(27.8 \%)$ & $4(4 \%)$ & $69(68.3 \%)$ & $3.38( \pm 1.01)$ & $22(37.3 \%)$ & $3(5 \%)$ & $34(57.7 \%)$ & $3.24( \pm 1.10)$ & $\mathrm{p}=0.441$ \\
\hline Total confidence score & - & - & - & $21.2( \pm 3.25)$ & - & - & - & $19.3( \pm 4.38)$ & $\mathrm{p}=0.005$ \\
\hline \multicolumn{10}{|l|}{$\begin{array}{l}\text { Barriers to } \\
\text { consultation }\end{array}$} \\
\hline $\begin{array}{l}\text { I don't have health } \\
\text { insurance }\end{array}$ & $89(88.1 \%)$ & $0(0 \%)$ & $12(11.9 \%)$ & $2.06( \pm 1.00)$ & $51(86.4 \%)$ & $0(0 \%)$ & $8(13.6 \%)$ & $2.14( \pm 0.99)$ & $\mathrm{p}=0.484$ \\
\hline $\begin{array}{l}\text { Consultations fees are } \\
\text { high }\end{array}$ & $88(87.1 \%)$ & $2(2 \%)$ & $11(10.9 \%)$ & $2.06( \pm 0.83)$ & $53(89.8 \%)$ & $1(1.7 \%)$ & $5(8.5 \%)$ & $2.08( \pm 0.81)$ & $\mathrm{p}=0.725$ \\
\hline $\begin{array}{l}\text { I spent lot of time } \\
\text { waiting when I consult a } \\
\text { health facility }\end{array}$ & $60(59.4 \%)$ & $2(2 \%)$ & $39(38.6 \%)$ & $2.84( \pm 1.18)$ & $44(74.6 \%)$ & $1(1.7 \%)$ & $14(23.7 \%)$ & $2.53( \pm 1.04)$ & $\mathrm{p}=0.106$ \\
\hline $\begin{array}{l}\text { The health facility is far } \\
\text { from my home }\end{array}$ & $81(80.2 \%)$ & $0(0 \%)$ & $20(19.8 \%)$ & $2.34( \pm 0.89)$ & $54(91.5 \%)$ & $0(0 \%)$ & $5(8.5 \%)$ & $2.14( \pm 0.60)$ & $\mathrm{p}=0.250$ \\
\hline $\begin{array}{l}\text { I don't have time to go } \\
\text { to a health facility }\end{array}$ & $71(70.3 \%)$ & $1(1 \%)$ & $29(28.7 \%)$ & $2.53( \pm 1.11)$ & $53(89.8 \%)$ & $0(0 \%)$ & $6(10.2 \%)$ & $2.03( \pm 0.76)$ & $\mathrm{p}=0.004$ \\
\hline Total barriers score & - & - & - & $11.8( \pm 3.18)$ & - & - & - & $10.9( \pm 2.69)$ & $\mathrm{p}=0.028$ \\
\hline
\end{tabular}

Non-self-prescribers: Parents/caregivers who choose drugs are dangerous". Access to pharmacy, traditionnot to self-medicate reported most frequently that they al healer, traditional medication shop or cost, were not don't use self-medication because "non-prescription found to be reasons to not use self-medication (Table 4).

Table 4: Reason for not using self-medication $(n=34)$

\begin{tabular}{|c|c|c|c|c|}
\hline Reasons & Disagree & Neutral & Agree & $\begin{array}{l}\text { Mean } \\
( \pm \text { SD }) \\
\end{array}$ \\
\hline Nonprescription drugs are dangerous & $6(17.7 \%)$ & $1(2.9 \%)$ & $\begin{array}{l}27 \\
(79.4 \%)\end{array}$ & $\begin{array}{l}3.82 \\
( \pm 0.96)\end{array}$ \\
\hline Nonprescription drugs do not work & $9(26.5 \%)$ & $3(8.8 \%)$ & $\begin{array}{l}22 \\
(64.7 \%)\end{array}$ & $\begin{array}{l}3.53 \\
( \pm 1.05) \\
\end{array}$ \\
\hline My child/children did not get sick & $\begin{array}{l}30 \\
(88.2 \%) \\
\end{array}$ & $0(0 \%)$ & $\begin{array}{l}4 \\
(11.8 \%) \\
\end{array}$ & $\begin{array}{l}2.18 \\
( \pm 0.93) \\
\end{array}$ \\
\hline I have limited access to pharmacy & $\begin{array}{l}33 \\
(97.1 \%) \\
\end{array}$ & $0(0 \%)$ & $1(2.9 \%)$ & $\begin{array}{l}1.94 \\
( \pm 0.48)\end{array}$ \\
\hline I can't afford medication in pharmacy & $\begin{array}{l}32 \\
(94.1 \%)\end{array}$ & $0(0 \%)$ & $2(5.9 \%)$ & $\begin{array}{l}1.88 \\
( \pm 0.68)\end{array}$ \\
\hline $\begin{array}{l}\text { I have limited access to traditional } \\
\text { medication shop/store }\end{array}$ & $\begin{array}{l}32 \\
(94.1 \%) \\
\end{array}$ & $1(2.9 \%)$ & $1(2.9 \%)$ & $\begin{array}{l}1.82 \\
( \pm 0.62) \\
\end{array}$ \\
\hline I have limited access to traditional healer & $\begin{array}{l}33 \\
(97.1 \%)\end{array}$ & $0(0 \%)$ & $1(2.9 \%)$ & $\begin{array}{l}1.76 \\
( \pm 0.51)\end{array}$ \\
\hline
\end{tabular}


Social demographic association with use of non-prescription drug: The association between different demographic characteristics and the use of self-medication was analyzed. In bivariate analysis the factors that were statistically significantly associated with use of non-prescription drugs included being from Kigali and having more than one child less than 10 years of age. In the multivariate analysis of factors that were significant in the bivariate analysis (with cut-off $\mathrm{p}<0.2$ ), the only factor associated with increased use of self-prescribed drugs was having more than 1 child under the age of 10 years (Table 5 ).

Table 5: Social demographic association with use of nonprescription drug

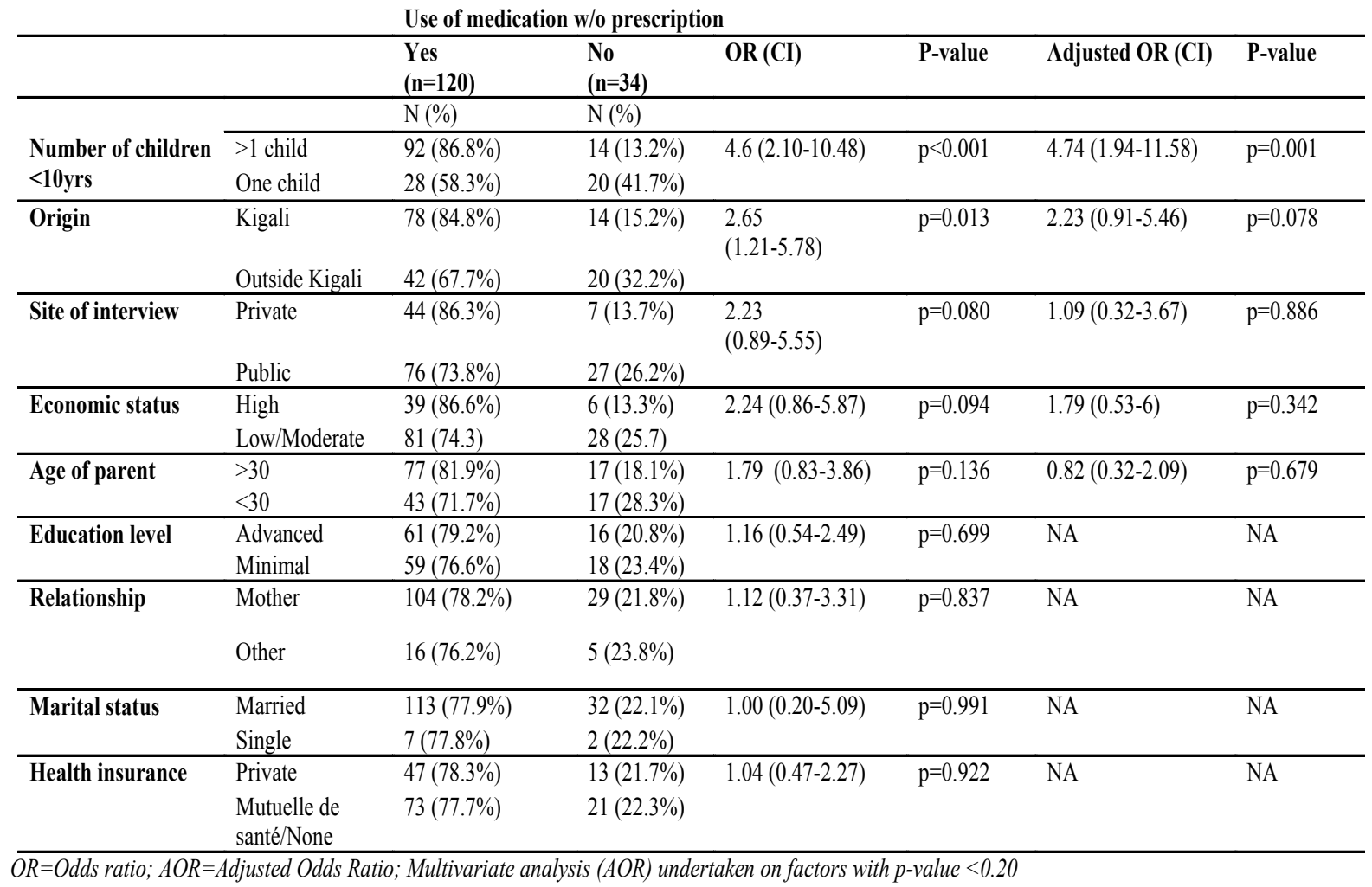

Association of socio-demographic factors with the use of modern versus. Traditional medication: The association between socio-demographic factors and the use of modern only vs. traditional only drugs was analyzed. In bivariate analysis the factors associated with use of exclusive modern rather than exclusive traditional drugs in self-medication were: caregivers in private clinic, caregivers from Kigali, advanced education, high social economic class, having private health insurance, and being older than 30 years. e included all factors with a $\mathrm{p}$-value $<0.2$ in a multivariate analysis and after adjusting for confounders only age above 30 and living in Kigali remained associated with the preference of exclusive modern self-medication compared to exclusive traditional self-medication (Table 6). 
Table 6: Social demographic association with type of self-medication used(modern vs. traditional)

\begin{tabular}{|c|c|c|c|c|c|c|c|}
\hline & & $\begin{array}{l}\text { Modern only } \\
(\mathrm{n}=61)\end{array}$ & $\begin{array}{l}\text { Traditional only } \\
(n=19)\end{array}$ & $\begin{array}{l}\text { OR } \\
(95 \% \mathrm{CI}) \\
\end{array}$ & p-value & $\begin{array}{l}\text { Adjusted } \\
\text { OR(CI) }\end{array}$ & $\mathrm{p}$-value \\
\hline & & $\mathrm{N}(\%)$ & $\mathrm{N}(\%)$ & & & & \\
\hline \multirow[t]{2}{*}{$\begin{array}{l}\text { Site of } \\
\text { interview }\end{array}$} & & $33(97.1 \%)$ & $1(2.9 \%)$ & $\begin{array}{l}21.21 \\
(2.66-169)\end{array}$ & $\mathrm{p}<0.001$ & $\begin{array}{l}0.61(0.02- \\
18.16)\end{array}$ & $\mathrm{p}=0.778$ \\
\hline & Public & $28(60.9 \%)$ & $18(39.1 \%)$ & & & & \\
\hline \multirow[t]{2}{*}{$\begin{array}{l}\text { Education } \\
\text { level }\end{array}$} & Advanced & $43(95.5 \%)$ & $2(4.4 \%)$ & $\begin{array}{l}20.3(4.24- \\
97.12)\end{array}$ & $\mathrm{p}<0.001$ & $\begin{array}{l}2.38(0.24- \\
22.92)\end{array}$ & $\mathrm{p}=0.453$ \\
\hline & Minimal & $18(51.4 \%)$ & $17(48.6 \%)$ & & & & \\
\hline \multirow[t]{2}{*}{$\begin{array}{l}\text { Economic } \\
\text { status }\end{array}$} & High & $30(96.7 \%)$ & $1(3.2 \%)$ & $\begin{array}{l}17.41 \\
(2.18- \\
138.77)\end{array}$ & $\mathrm{p}=0.001$ & $\begin{array}{l}4.75(0.32- \\
70.28)\end{array}$ & $\mathrm{p}=0.257$ \\
\hline & $\begin{array}{l}\text { Low } \\
\text { /Moderate }\end{array}$ & $32(63.2)$ & $18(36.7)$ & & & & \\
\hline \multirow[t]{2}{*}{$\begin{array}{l}\text { Health } \\
\text { insurance }\end{array}$} & Private & $38(95 \%)$ & $2(5 \%)$ & $\begin{array}{l}14.04 \\
(2.96- \\
66.42)\end{array}$ & $\mathrm{p}<0.001$ & $\begin{array}{l}2.78(0.20- \\
37.44)\end{array}$ & $\mathrm{p}=0.440$ \\
\hline & $\begin{array}{l}\text { Mutuelle } \\
\text { de } \\
\text { santé/none }\end{array}$ & $23(57.5 \%)$ & $17(42.5 \%)$ & & & & \\
\hline \multirow[t]{2}{*}{$\begin{array}{l}\text { Age of } \\
\text { parent }\end{array}$} & $>30$ & $49(89.1 \%)$ & $6(10.9 \%)$ & $\begin{array}{l}8.84(2.78- \\
28.08)\end{array}$ & $\mathrm{p}<0.001$ & $\begin{array}{l}5.78(1.25- \\
26.68)\end{array}$ & $p=0.025$ \\
\hline & $\leq 30$ & $12(48 \%)$ & $13(52 \%)$ & & & & \\
\hline \multirow[t]{2}{*}{ Origin } & Kigali & $46(90.2 \%)$ & $5(9.8 \%)$ & $\begin{array}{l}8.5(2.65- \\
27.82)\end{array}$ & $\mathrm{p}<0.001$ & $\begin{array}{l}8.2(1.58- \\
43.12)\end{array}$ & $p=0.012$ \\
\hline & $\begin{array}{l}\text { Outside } \\
\text { Kigali }\end{array}$ & $15(51.7 \%)$ & $14(48.2 \%)$ & & & & \\
\hline \multirow{2}{*}{$\begin{array}{l}\text { Number of } \\
\text { children } \\
<10 \mathrm{yrs}\end{array}$} & >one & $49(79 \%)$ & $13(21 \%)$ & $\begin{array}{l}1.88(0.59- \\
5.98)\end{array}$ & $\mathrm{p}=0.281$ & NA & NA \\
\hline & One & $12(66.6 \%)$ & $6(33.3 \%)$ & & & & \\
\hline \multirow[t]{2}{*}{ Relationship } & Other & $11(84.6 \%)$ & $2(15.4 \%)$ & $\begin{array}{l}1.87(0.37- \\
9.29)\end{array}$ & $\mathrm{p}=0.442$ & $\mathrm{NA}$ & NA \\
\hline & Mother & $50(74.6 \%)$ & $17(25.4 \%)$ & & & & \\
\hline \multirow[t]{2}{*}{$\begin{array}{l}\text { Marital } \\
\text { status }\end{array}$} & Married & $59(76.6 \%)$ & $18(23.4 \%)$ & $\begin{array}{l}1.63(0.14- \\
19.14)\end{array}$ & $\mathrm{p}=0.693$ & NA & NA \\
\hline & Single & $2(66.7 \%)$ & $1(33.3 \%)$ & & & & \\
\hline
\end{tabular}

\section{Discussion}

This study aimed to determine the reported self-medication use in children in private and public health facilities in Rwanda and to determine attitudes and reasons associated with parental decisions to self-medicate their children. Our study showed that $78 \%$ of participants have used self-medication for their children. Both modern and traditional drugs were used. This is similar to $77 \%$ reported in Pakistan ${ }^{7}$ and higher than the prevalence of $32 \%$ and $58.82 \%$ reported in Madagascar and India ${ }^{8,11,16}$. However, higher prevalence of $95.1 \%$ and 98.1\% were reported in Greece and Australia ${ }^{17,18}$. This shows that self-medication in children is a universal practice with some differences between countries.

In our study $51 \%$ of parents/caregivers who used self-medication used only modern medicines, $16 \%$ used only traditional self-medicines and 33\% used both. Our findings show that we had a lower rate of parents/car- egivers who used only modern medicines compared to previous studies conducted in Sudan and Saudi Arabia where $84 \%$ and $86.7 \%$ of parents/caregivers reported using modern medicines over traditional ones ${ }^{23,24}$; this difference can be explained by the fact that in our study we separately analyzed participants who used both types of self- medication, and did not attempt to specify whether they preferred modern or traditional drugs.

Self-medication has many potential benefits, for example medications such as paracetamol can be effectively used. However, self-medication can result in ineffective medications being used, wasting parental resources and potentially delaying a child receiving appropriate care. Cough syrups were the second most widely used selfmedication. This is of concern, particularly in young children as cough suppressants in this age group are known to be ineffective and to have potentially harm- 
ful effects ${ }^{27}$. Drugs for intestinal worms were the third most commonly used in self-medication. Clinical experience of the authors demonstrates that parents/caregivers may be attributing many other symptoms such as decreased appetite, poor weight gain as being caused by intestinal worms and therefore use of drugs for suspected intestinal worms without prior consultation may be inappropriate. Most alarming in our results was the finding that nearly $20 \%$ of parents/caregivers were self-medicating their children with antibiotics. As the world aims to combat antibiotic resistance, this form of self-medication should be addressed.

There is a difference between education and economic factors associated with the choice to self-medicate. Studies from Spain, Finland, Italy, and Madagascar $15,16,28,29$, found that families with high income and with secondary and higher education level practice more self-medication than families with low income and low education level. On the other hand in a study done in India, family income and parental education were not significantly influencing self-medication practice, in Germany, mother with lower education level used fewer OTC and no significant difference was seen with regard to income status ${ }^{11,30}$. In our study, financial, insurance or geographical access barriers were not reasons to choose self-medication. This finding is not surprising as $58 \%$ of our participants had Mutuelle de santé insurance, and access to healthcare in Rwanda is overall good with $79 \%$ of the population subscribing to an affordable community health insurance (Mutuelle de Santé) which covers $90 \%$ of consultation fees in public health facilities ${ }^{31}$.

Furthermore, our study showed that having more than one child less than 10 years of age was associated with the practice of self-medication. No other factor was shown to be associated with parental use of self-medication. Caregiver's age above 30 years of age were found to be associated with the use of modern self-medication compared to traditional ones. In contrast to our findings, being female and younger were associated with the practice of self-medication in Italy and Spain ${ }^{15,28}$.

We observed that coming from Kigali city was associated with the preference of modern drugs over traditional ones, which can be explained by the fact that most of our study participants were from Kigali where there is a wider availability of pharmacies dispensing modern medicines than in areas outside Kigali.

\section{Limitations}

Our analysis to identify associated factors did not include the group of parents/caregivers who used both types of self-medication. The internal validity could have been compromised by the high rate of verbal completion of the questionnaire, with participants being potentially prone to acquiescence bias. Recall bias may have also limited caregiver responses. All regional provinces of Rwanda were not represented.

\section{Conclusion}

Self-medication, a worldwide practice, is also common in Rwanda. Parents/caregivers are involved in this practice for their children regardless of their socio-demographic background. Consideration should be given to regulating drugs used in self-medication as well as the education of the population with the goal of minimizing the risks of self- medication and maximizing benefits.

\section{Ethical considerations}

Confidentiality: The study respected confidentiality using a Unique Patient Identifier (UPI) code; the questionnaires were anonymous and included no personal identifiers. Consent forms were linked to the study participant using the UPI. The paper-versions of the completed questionnaires and consent forms were kept in a safe/locked environment and the database was password protected with limited access. As the questionnaires were completed in the waiting rooms of the facilities, there was a small possibility of other parents / caregivers overhearing the responses.

Informed consent: Participants were given verbal explanation of the study and time to ask questions. The participants were informed that there was no consequence on the care given to in the clinic or hospital whether or not they chose to participate and that they could withdraw at any time without any consequences. A written consent form was signed before enrollment into the study.

Risks to participants: There were no significant physical, social, emotional, financial, or legal risks to participants identified.

Ethical approval: The project was approved by the University of Rwanda Pediatric Academic Department on $27^{\text {th }}$ April 2018 and Institutional Review Board (IRB) of the CMHS (College of Medicine and Health 
Sciences) (Ref: No244/CMHS IRB/2018) on 10th July 2018. Approvals from Health care facilities included in study were obtained before the study was conducted.

Funding and sponsors: The project team neither sought nor gained any funding

Incentive to participants: No incentives were given to participants

Potential conflicts of interest: One of the co-investigators $(\mathrm{CU})$ is employed at a private clinic included in the study

\section{Acknowledgments}

Dr Jean-Claude Kabayiza for his input into the study design.

\section{List of acronyms of terms}

CMHS: College of Medicine and Health Sciences

CU: Christian Umuhoza

HC: Health Center

IRB: Institutional Review Board

JU: Joyeuse Ukwishaka

NM: Natalie McCall

NSAID: Non-Steroidal Anti-Inflammatory Drugs

OPD: Out Patient Department

OTC: Over the Counter

PC: Peter Cartledge

PI: Principal Investigator

UTHK: University Teaching Hospital of Kigali

WHO: World Health Organization

\section{References}

1. Gillam S. Is the declaration of Alma Ata still relevant to primary health care ? BMJ. 2008;336:536-8 PubMed.

2. Okoro C. Primary Health Care in London : onwards from Alma Ata. London J Prim Care (Abingdon). 2008;1:61-5.

3. UNICEF World Health Organization. Declaration of Alma Ata: International Conference on Primary Health Care, Alma Ata, USSR, 6-12 September 1978. Amercan J Public Heal. 2015;105(6):1094-5.

4. Kumar V, Mangal A, Yadav G, Raut D, Singh S. Prevalence and pattern of self-medication practices in an urban area of Delhi, India. Med J Dr DY Patil Univ. 2015;8(1):16-20.

5. Osemene KP, Lamikanra A. A Study of the Prevalence of Self-Medication Practice among University Students in Southwestern Nigeria. Trop J Pharm Res August. 2012;11(4):683-9.
6. Abebe Dilie, Tenaw Gualu DH and FAZ, Department. Knowledge, attitude and practice of self - medication among health science students at Debre Markos. J Public Heal Epidemiol Full. 2017;9:106-13 PubMed .

7. Gohar UF, Khubaib S, Mehmood A. Self-Medication Trends in Children by their Parents. J Dev drugs. 2017;6(2):1 PubMed -7.

8. Naaraayan SA, Rathinabalan I, Seetha V. Self-medication pattern among children attending a tertiary hospital in South India : a cross-sectional study. Int J Contemp Pediatr. 2016;3(4):1267-71.

9. WHO. Traditional Medicine Strategy 2014-2023. 2013.

10. WHO. Global report on traditional and complementary medicine 2019. 2019.

11. Dr. Smita Sontakke, Dr. Ayudha Magdum, Dr. Kavita Jaiswal, Dr. Chaitali Bajait, Dr. Sonali Pimpalkhute DGD. "Evaluation Of parental perception about self-medications and other medicine use practices in children ." Eur J Pharm Med Res. 2015;2(7):179 PubMed -85 .

12. Fielding S, Porteous T, Ferguson J, Maskrey V, Blyth A, Paudyal V, et al. Estimating the burden of minor ailment consultations in general practices and emergency departments through retrospective review of routine data in North East Scotland. Fam Pract. 2015;32(2):165 PubMed -72 .

13. WHO, Guideline for the Regulatory Assessment of Medicinal Poducts for use in Self-Medication. 2000. p. 1-28.

14. Aslam M, Ali M, Mushtaq D, Zaid M, Riaz M, Nasir A. Parent-based self-medication in Pakistani children: A qualitative cross-sectional survey. Bangladesh J Med Sci. 2016;15(1):33-8.

15. Garofalo L, Giuseppe G Di, Angelillo IF. Self-Medication Practices among Parents in Italy. Biomed Res Int. 2015;2015:1-8 PubMed .

16. Tsifiregna RL, Razafimahatratra SH, Raveloharimino NH, Rakotomalala RLH, Ravelomanana N. Self-medication practice among children in Antananarivo , Madagascar. Internatinal J Res Med Sci. 2016;4(12):5172-5.

17. Trajanovska M, Manias E, Cranswick N, Johnston L. Use of over-the-counter medicines for young children in Australia. J Paediatr Child Health. 2010;46(1-2):5-9.

18. Andritsou F, Benetou V, Michail KA, Pantazis N, Pavlopoulou ID. Out-of-Hospital Administration of Medication without Prescription and Associated Factors among Preschool Children. Biomed Res Int. 2017;2017:1-9 PubMed .

19. Levson G, Monjeza U. People' s knowledge, attitude and practice's about self medication and its impli- 
cations in ilala municipality, Dar es salaam. 2013. 1-69 p.

20. Uwamahoro A. Parental knowledge, perceptions and management of chidhood fever in a vaccination clinic in Kigali. 2017. p. 49.

21. Umuhoza C, Karambizi AC, Tuyisenge L, Cartledge P. Caregiver delay in seeking healthcare during the acute phase of pediatric illness, Kigali, Rwanda. Panafrican Med J. 2018;8688:1-10 PubMed .

22. Von Elm E, Altman DG, Egger M, Pocock SJ, Gøtzsche PC, Vandenbroucke JP. The Strengthening the Reporting of Observational Studies in Epidemiology (STROBE) statement: Guidelines for reporting observational studies. PLoS Med. 2007;4(10):1623 PubMed $-7$.

23. Eldalo AS, El-hadiyah TMH, Yousif MA. Sudanese parents ' knowledge, attitudes and practice about self medication to their children : Qualitative study. Saudi J Heal Sci. 2013;2(2):103 PubMed -7.

24. Eldalo AS. Saudi parent's attitude and practice about self-medicating their children. Arch Pharm Pract. 2013;4(2):57 PubMed -62.

25. Gray NJ, Boardman HF, Symonds @bullet B Sue, Gray NJ, Boardman HF, Symonds BS. Information sources used by parents buying non-prescription medicines in pharmacies for preschool children. Int J Clin Pharm [Internet]. 2011 [cited 2018 Jan 17];33:842-8.
Available from: https://link.springer.com/content/pdf/10.1007\%2Fs11096-011-9547-5.pdf

26. Naing L WT and RB. Sample Size Calculator for Prevalence Studies, Version 1.0.01. [Internet]. 2016. Available from: http://www.kck.usm.my/ppsg/stats_ resources.htm

27. Lowry JA, Leeder JS. Over-the-Counter Medications : Update on Cough and Cold Preparations. Pediatr Rev. 2019;36(7):286-98.

28. Martín-Pérez M, López De Andrés A, Barcenilla González MÁ, Jiménez-García R, Hernández-Barrera V, Jiménez-Trujillo I, et al. Parental administration of over-the-counter medication to Spanish children: A population-based national study. I Spec Pediatr Nurs. 2016;21(2):64-73.

29. Hämeen-Anttila K, Halonen P. Parental attitudes toward medicine use in children in Finland. Int J Clin Pharm [Internet]. 2011 [cited 2018 Jan 17];33:849-858. Available from: https://link.springer.com/content/pdf/10.1007\%2Fs11096-011-9549-3.pdf

30. Italia S, Brand H, Heinrich J, Berdel D, Berg A Von, Wolfenstetter SB. Utilization of complementary and alternative medicine ( CAM ) among children from a German birth cohort ( GINIplus ): patterns , costs, and trends of use. BMC Complement Altern Med. 2015;15(49):1-10.

31. National Institute of statistics. Rwanda Demographic and Health Survey. Rwanda. 2014. 640 p. 